\title{
Cidade dentro da cidade: \\ Organização Espacial no Cemitério Vera Cruz, Passo Fundo RS
}

A Town inside the City:

Spatial organization in the Vera Cruz graveyard in Passo Fundo RS

Ciudad dentro de la ciudad:

Organización Espacial en el Cementerio Vera Cruz, Passo Fundo RS

Mirian Carasek

Professora Mestre Arquiteta, UPF, Brasil. miriancarasek@upf.br

Greice Barufaldi Rampanelli Professora Mestre Arquiteta, UPF, Brasil greiceb@upf.br

Maria Anita da Silva Graduanda em Arquitetura, UPF, Brasil 118919.silva@gmail.com 


\section{RESUMO}

O objetivo deste estudo é avaliar a organização espacial do Cemitério Vera Cruz, em Passo Fundo/RS, para que sirva de base informativa para as propostas do Plano Diretor do cemitério, instrumento de planejamento já sugerido pela Prefeitura Municipal. Para tanto, o trabalho foi dividido em dois níveis de análise: macro e micro. A análise macro diz respeito à relação entre a cidade e o cemitério e o cemitério e seu entorno imediato. Assim, primeiramente, foram estabelecidas as relações de ocupação do espaço intermediário entre cidade e cemitério. Após, foram analisadas as vias e construções que o contornam, evidenciando a presença de um importante conjunto cemiterial. A análise micro, por sua vez, direcionou-se à área específica do campo santo a abordagem levou a questões como a localização e condição dos acessos; a hierarquia das vias quanto ao fluxo e utilização efetiva; a análise dos lotes tumulares e dos ambientes de permanência, - existentes ou não. O Cemitério Vera Cruz apresenta algumas condições específicas, também abordadas no estudo, o caso do túmulo de Maria Elizabeth, que concentra visitantes e sobrecarrega o fluxo local. Junto disso, apresentam-se diversas tipologias tumulares, bem como sua tendência de verticalização. Complementarmente, o trabalho analisa as condições atuais de iluminação, segurança e higiene do cemitério, sob a ótica da promoção de visitas guiadas à toda população, no sentido de evidenciar a importância da preservação da história local. A metodologia adotada perpassa pela pesquisa historiográfica, visitas e levantamentos in loco, registro fotográfico, entrevistas e comparações com outros ambientes similares.

PALAVRAS-CHAVE: Cemitério. Plano Diretor. Passo Fundo.

\section{ABSTRACT}

The objective of this study is to evaluate the spatial organization of Vera Cruz graveyard in Passo Fundo/RS, to serve as an information base for the proposals of its Master Plan, a planning tool already suggested by the City Hall. For that, the work was divided into two levels of analysis: macro and micro. The macro analysis concerns the relationship between the city and the graveyard and its immediate surroundings. Then, the routes and constructions in its surrounds were analyzed evidencing the presence of an important set. The micro analysis, on the other hand, was directed to the specific area of the cemetery, the approach led to questions such as the location and condition of accesses; the hierarchy of routes and their effective flow and use; the analysis of tombstones and any stay areas, - existing or not. The Vera Cruz graveyard presents some specific conditions, as well, that were also addressed in this study, the case of the Maria Elizabeth's tomb, which concentrates visitors and overloads the local flow. In addition, the work presents the several types of tombs, as well as their tendency to verticalization. Also, the current conditions of illumination, safety and hygiene of the graveyard, from the point of view of the promotion of guided visits to the entire population, to highlight the importance of preserving local history. The methodology adopted is based on historiography research, visits and surveys in loco, photographic record, interviews and comparisons with other similar environments.

KEY WORDS: Graveyard. City Plans. Passo Fundo.

\section{RESUMEN}

El objetivo de este estudio es evaluar la organización espacial del Cementerio Vera Cruz, en Passo Fundo / RS, para que sirva de base informativa para las propuestas del Plan Director del cementerio, instrumento de planificación ya sugerido por el Ayuntamiento Municipal. Para ello, el trabajo se dividió en dos niveles de análisis: macro y micro. El análisis macro se refiere a la relación entre la ciudad y el cementerio y el cementerio y su entorno inmediato. Así, primero, se establecieron las relaciones de ocupación del espacio intermedio entre ciudad y cementerio. Después, se analizaron las vías y construcciones que lo rodean, evidenciando la presencia de un importante conjunto cementerial. El análisis micro, a su vez, se dirigió al área específica del camposanto el abordaje llevó a cuestiones como la localización y condición de los accesos; la jerarquía de las vías en cuanto al flujo y utilización efectiva; el análisis de los lotes tumulares y de los ambientes de permanencia, - existentes o no. El Cementerio Vera Cruz presenta algunas condiciones específicas, también abordadas en el estudio, el caso de la tumba de María Elizabeth, que concentra visitantes y sobrecarga el flujo local. Junto a ello, se presentan diversas tipologías tumulares, así como su tendencia de verticalización. Complementariamente, el trabajo analiza las condiciones actuales de iluminación, seguridad e higiene del cementerio, bajo la óptica de la promoción de visitas guiadas a toda la población, en el sentido de evidenciar la importancia de la preservación de la historia local. La metodología adoptada pasa por la investigación historiográfica, visitas y levantamientos in loco, registro fotográfico, entrevistas y comparaciones con otros ambientes similares.

PALABRAS CLAVE: Cementerio. Plan Maestro. Passo Fundo. 


\section{Introdução}

Na concepção urbanística tradicional, a cidade pode ser entendida como o lugar que concentra oferta de serviços - culturais, religiosos, de infraestrutura ou consumo - e que reúne diversas atividades humanas. Segundo Leonardo Benévolo (2006), esta sobreposição de funções se deve às diferentes realizações de seus habitantes ao longo do tempo, que passam a se justapor no ambiente urbano para adaptar a estrutura às necessidades e interesses diversos. Os espaços da cidade podem ser considerados estratégicos a fim de dinamizar a ambiência auxiliando, assim, em sua otimização social, econômica e ambiental. Sob essa perspectiva, o espaço destinado aos mortos deve ser incluído nesta categoria.

Para Lewis Mumford (1998), foi a necessidade de estabelecer uma morada para os mortos o primeiro passo para que os grupos nômades primitivos se estabelecessem formando os grupamentos urbanos iniciais: "Os mortos foram os primeiros a ter uma morada permanente: uma caverna, uma cova assinalada por um monte de pedras, um túmulo coletivo. Constituíam marcos aos quais provavelmente retornavam os vivos, a intervalos, a fim de comungar com os espíritos ancestrais ou de aplacá-los". É com a morte que o homem cria os cemitérios; que nos revelam diferentes sociedades através dos séculos. Ao longo dos anos, a morte assume diferentes formas: no período medieval, a Igreja tinha o poder de controle sobre a vida e a morte de seus fiéis, mas já na metade do séc. XVIII, ela perde este controle. A partir de então, tumbas não devem mais ser compartilhadas, pois além da necessidade de preservar a individualidade, há a questão higiênica a ser considerada. Harouel, em História do Urbanismo (2004) mostra a preocupação com a circulação do ar, acompanhada do cuidado para com o saneamento básico; a preocupação quanto ao deslocamento de matadouros, prisões, hospitais e cemitérios para locais distantes da área urbana. No século 18 são proibidos os sepultamentos dentro das igrejas, há a transferência dos cemitérios, por serem insalubres, para fora das aglomerações urbanas. (HAROUEL, 2004). Nos dias atuais, os cemitérios estão localizados nos perímetros urbanos ou até mesmo, envolvidos pelas moradias. Eles reproduzem a geografia da sociedade local e definem a divisão socioeconômica.

O cemitério nos revela, a partir de sua análise, que não é uma simples morada dos mortos ou local de mitos e medo. Ele envolve toda uma questão de sentimento, de dor, de preservação da memória familiar, da cultura, da crença religiosa, do contexto socioeconômico, além de mostrar a organização e divisão dos mausoléus, túmulos e gavetas e da própria cultura artística exposta, revelando a imagem e o presente de uma sociedade local.

Nesse sentido, o patrimônio histórico, como elemento fundamental representativo da história de uma sociedade, é todo bem produzido no decorrer de sua existência de significativa importância como elemento de memória que tem por objetivo entender sua cultura, seus hábitos e características no passado, respeitando as formas de produção que essa mesma sociedade desenvolveu para deixar como legado. No caso da cidade de Passo Fundo/RS, nos últimos anos, surgiram grandes iniciativas no sentido da preservação de espaços cemiteriais. Um 
deles é o Projeto Museu a Céu Aberto, que visa a preservação e a valorização de um ambiente específico: o Cemitério Municipal Vera Cruz. O projeto visa demonstrar a força do vínculo dos vivos com os mortos, numa associação simbólica das pessoas com o lugar. Nesse sentido, a necessidade de preservação do Patrimônio Cultural tem sido muito discutida - a valorização do passado e memória coletiva das cidades são parte do patrimônio arquitetônico e representam a produção simbólica e material, capaz de expressar as experiências de uma sociedade. Sendo assim, com vistas a viabilização do projeto, são realizadas iniciativas como o curso para formação de guias de visitação do cemitério, que acompanham a comunidade em um passeio na área central do cemitério, onde há inúmeros túmulos importantes.

Edgar Morin (1997) se refere às formas de linguagem humana, referindo-se às palavras e aos símbolos como o "cosmo de bolso" do ser humano. O símbolo é uma coisa abstrata, ou particular, que contém em si todo o concreto e toda a riqueza. Desse modo, as palavras e os símbolos vão se tornando o cosmo de bolso do ser humano.

Tendo em vista essa relação do ser humano com os espaços cemiteriais, percebe-se em Passo Fundo, constante reclamação da falta de espaço nos cemitérios. O município possui oito cemitérios municipais e, com exceção do Jardim da Colina, a Secretaria de Transportes e Serviços Gerais (STSG) garante que todos os outros estão lotados. No entanto, a população questiona e salienta que há sim vários espaços vagos nos cemitérios que não são liberados para familiares com entes queridos falecidos. Um plano diretor para os cemitérios, no que se refere às ocupações de espaço e regras para construção dos jazigos, túmulos, gavetas e capelas, apresenta-se como necessidade para a comunidade.

Entendendo a importância da adequação e preservação dos espaços cemiteriais para a sociedade, o objetivo principal deste estudo é avaliar a organização espacial do Cemitério Vera Cruz, em Passo Fundo/RS, para que sirva de base informativa para as propostas do Plano Diretor do cemitério, instrumento de planejamento já sugerido pela Prefeitura Municipal, bem como evidenciar a necessidade da preservação dos bens arquitetônicos históricos e culturais existentes no local.

A metodologia adotada para esta pesquisa, perpassa pela pesquisa historiográfica, pesquisa a legislações pertinentes, visitas e levantamentos in loco, registro fotográfico, entrevistas e comparações com outros ambientes similares.

A apresentação dos resultados obtidos acontece em dois níveis de análise: macro e micro (que será abordada adiante): $A$ análise macro diz respeito à relação entre a cidade e o cemitério e o cemitério e seu entorno imediato (figura 1). Assim, primeiramente, são estabelecidas as relações de ocupação do espaço intermediário entre cidade e cemitério, no que tange ao contexto de crescimento urbano. São verificadas as vias e as construções que contornam o cemitério, evidenciando a presença de mais equipamentos urbanos de mesmo uso próximos, configurando um importante conjunto. Além disso, foram observadas as vias próximas e as de acesso ao cemitério Vera Cruz. 


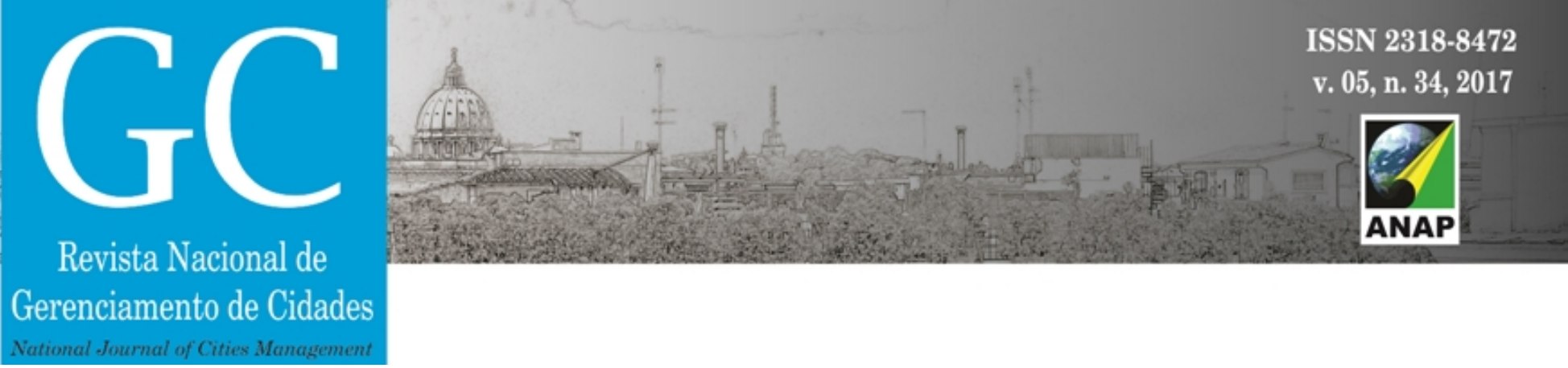

Já a análise micro direciona-se à área específica do cemitério, onde serão abordadas questões como a localização e condição dos acessos; a hierarquia das vias quanto ao fluxo e utilização efetiva; a análise dos lotes tumulares e dos ambientes de permanência - existentes ou não; como se pode observar na Figura 2.

\section{Um ambiente sempre guarda relações com seu entorno: Cemitério e entorno} "O lugar guarda em si e não fora dele o seu significado"

A pesquisa histórica permite dizer que o cemitério atualmente denominado Vera Cruz foi o primeiro campo santo público municipal de Passo Fundo. Anteriormente à 1902, os mortos eram sepultados na área central da cidade - na quadra ao lado de onde hoje está a Catedral Metropolitana Nossa Senhora Aparecida. A alteração do local ocorreu por diversos motivos, incluindo a chegada da ferrovia. Da área central, o cemitério passa a ocupar área localizada no bairro que recebeu mesmo nome, sendo atualmente considerado um dos principais do município.

Figura 1 Implantação do cemitério Vera Cruz e suas relações com os demais cemitérios

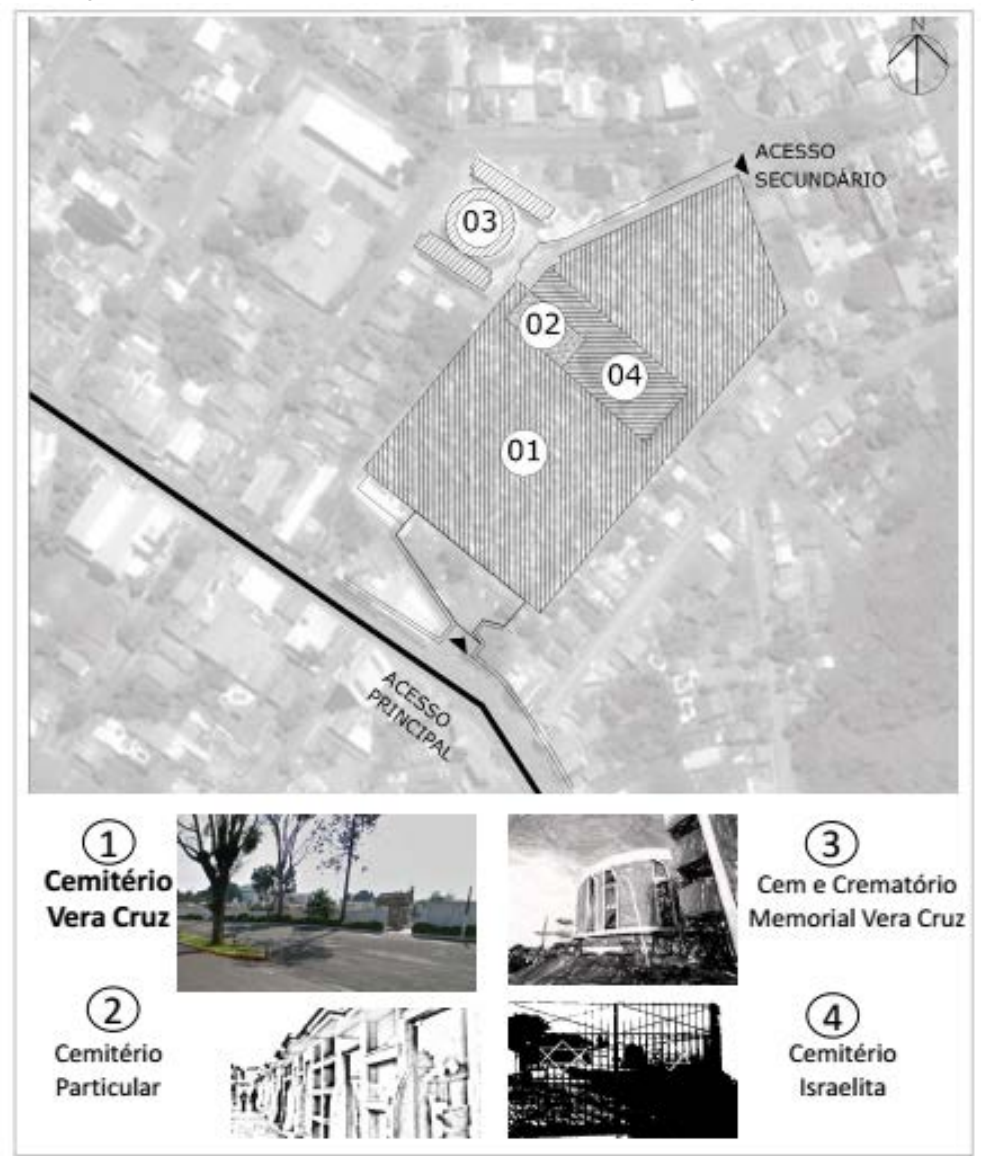

Fonte: Imagem aérea Google, cedido pela Prefeitura Municipal adaptados pelas autoras, 2017

${ }^{1}$ CARLOS, Ana Fani Alessandri. O lugar no/do mundo. São Paulo: Hucitec, 1996 
O cemitério Vera Cruz encontra-se afastado do centro da cidade, mas seu acesso é facilitado devido as vias que o circundam. A via de acesso principal é classificada como arterial, pois conforme o Código de Trânsito Brasileiro (1997), apresenta vias perpendiculares; equipamentos de controle de tráfego, como semáforos; permite acesso aos lotes lindeiros e às vias locais; além de fazer a conexão com as outras regiões da cidade. Esta via liga o Bairro Vera Cruz com o centro da cidade, com bairros próximos e com a BR 285, possuindo fluxo intenso de veículos leves, pesados, de pedestres e de transporte público. Até o acesso principal do cemitério, a rua em questão denomina-se Teixeira Soares. A partir dali, chama-se Avenida Moacir da Mota Fortes, que encontra a aproximadamente, quatro quadras adiante, a Avenida Rio Grande, que se estende até a Santa Cruz, via de acesso à BR 285. O acesso posterior é realizado através de via local, denominada da Rua Eduardo Roça, abastecida por uma via coletora denominada Rua Itaqui, que passa a ser Rua Erexim e encontra-se com a Rua Moacir da Mota Fortes. Essas características evidenciam a importância das ruas e avenidas do entorno do cemitério para a mobilidade urbana de Passo Fundo.

Por estar inserido em um grande bairro de Passo Fundo, o cemitério pertence a um ambiente urbano consolidado (como se pode observar na Figura 1), constituído de infraestrutura e atividades comerciais, institucionais, de serviços, além de espaços de lazer que atendem ao uso predominante na região: residencial. Em relação ao bairro, o cemitério provoca grande impacto, especialmente por seu uso diferenciado e grande área construída. Contudo, esses aspectos são potencializados pela presença de mais três cemitérios que mantem ligação física direta com o primeiro, formando um importante conjunto. 


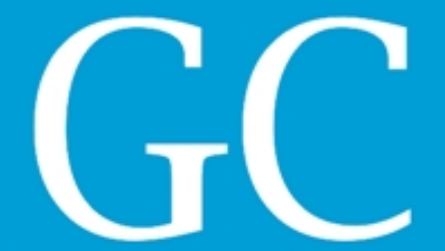

Revista Nacional de

Figura 2 Planta do cemitério, indicando ambientes vias de circulação e acessos

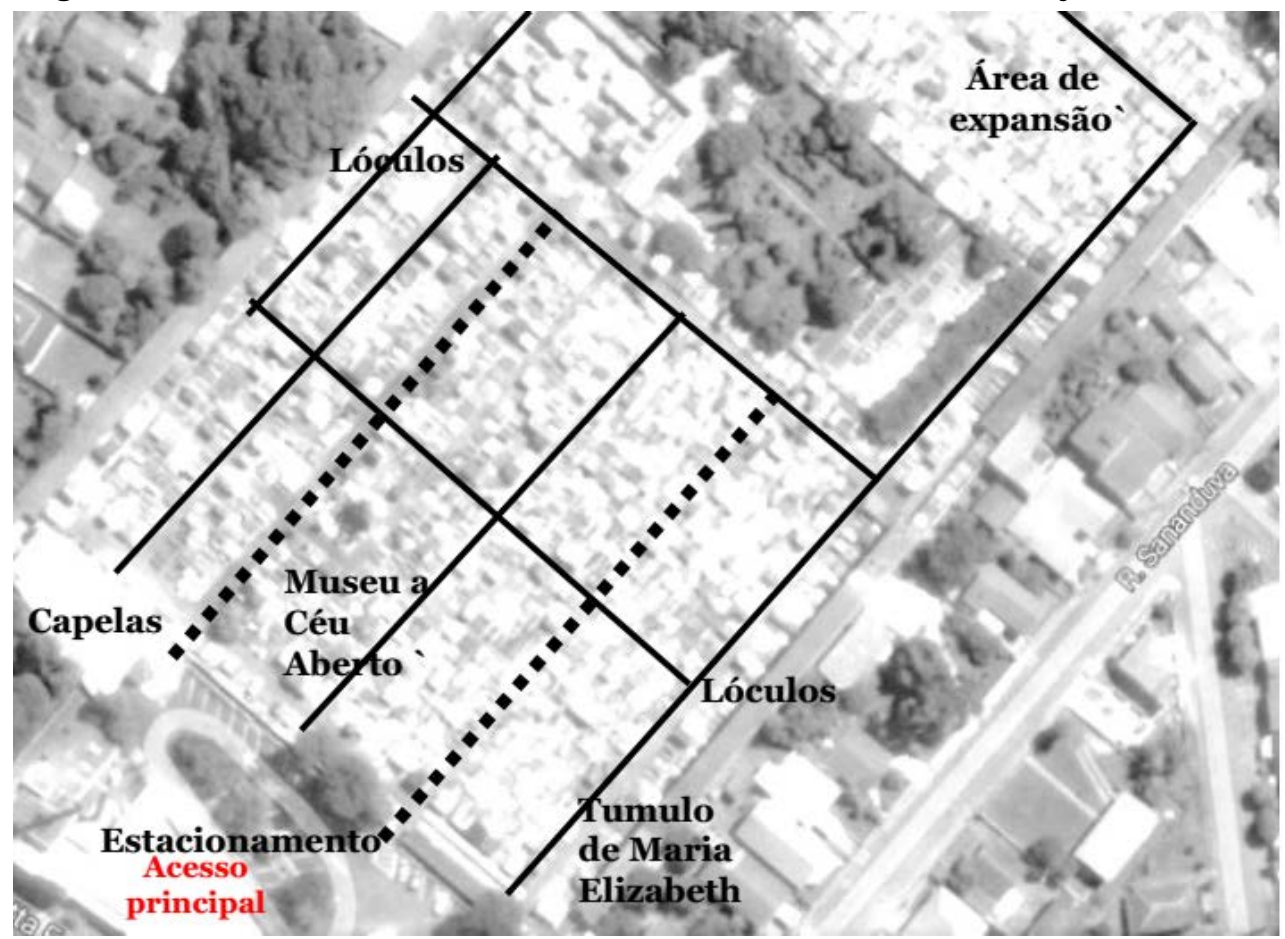

Fonte: Adaptado de Google Maps pelas autoras, 2015

Contornados pelo objeto de estudo, encontram-se o cemitério Israelita, um cemitério particular e ainda o Cemitério Memorial Vera Cruz. Seguindo pela Rua Eduardo Rocca tem-se um acesso secundário a todos os cemitérios do conjunto, inclusive ao cemitério Memorial Vera Cruz, - o último a ser construído dentre os quatro, e com acesso principal à rua Erechim, com uma proposta conceitual referente aos espaços cemiteriais distinta das já existentes. Enquanto os três primeiros configuram-se principalmente pelo uso de túmulos e/ou jazigos, com alguns espaços para gavetas, todos construídos a céu aberto, o mais recente deles, é um prédio de quatro pavimentos, todos cobertos, por onde distribuem-se as capelas mortuárias e os lóculos, fazendo com que a construção se destaque na paisagem urbana, servindo como ponto de referência para a localização de todo o conjunto de cemitérios.

O Plano Diretor de Desenvolvimento Integrado de Passo Fundo entende a área dos cemitérios como Zona de Uso Especial (ZUE), ou seja, que exige "regulamentação urbanística diferenciada da zona em que estiver inserida por suas características peculiares" (PDDI, 2006, p. 22). Junto disso, PDDI (2006, p.35), fixa que nas ZUE "as edificações obedecerão a regime urbanístico próprio a ser definido em lei, com o parecer favorável dos conselhos municipais pertinentes".

\section{O cemitério como um organismo}

Pode-se considerar o cemitério como mais um organismo vivo inserido dentro da cidade. Entendendo que um sistema urbano sem planejamento se torna um ambiente desagradável, 
insalubre e ocioso, que além de prejudicar o sistema como um todo e não garantir o suporte necessário aos familiares que estão em busca de um lugar consolável para deixar seus entes queridos, também traz problemas de cunho social, como a marginalização das áreas, estabelecer ações de gerenciamento desses espaços é essencial.

A figura 2 ilustra a análise micro, voltada à análise de aspectos como a localização e condição dos acessos; a hierarquia das vias quanto ao fluxo e utilização efetiva; a análise dos lotes tumulares e dos ambientes de permanência.

De acordo com pesquisas realizadas junto à Divisão de Cemitérios Municipal, órgão administrado pela Prefeitura Municipal, e informações cedidas, constatou-se que há mais de setenta mil corpos sepultados nesse local e que a média de sepultamentos do ano de 2013 foi de trezentos a trezentos e cinquenta. Tanto os lotes quanto as quadras destinadas aos sepultamentos não possuem uma medida padrão, tampouco as quadras possuem medida definida. Com base nos levantamentos feitos no local, podemos destacar uma distribuição espacial diversificada quando se trata do alinhamento entre as sepulturas, variando de uma quadra para outra.

Em locais onde a acessibilidade não é prioridade, o risco de acidentes e a insatisfação dos visitantes aumenta e, pode culminar em reclamações e eventuais processos pelos acidentes acontecidos.

A acessibilidade é um direito de todas as pessoas, tenham elas qualquer deficiência ou não; este é um direito garantido pelo Estatuto da Pessoa com Deficiência (BRASIL, 2015). A promoção da acessibilidade de pessoas aos espaços públicos e privados de uso coletivo tais como parques, sanitários públicos, veículos de transporte coletivo, comércios, cemitérios, é tarefa complexa, desgastante e burocrática. $O$ direito a circular livremente, independentemente da facilidade motora nada mais é que um direito; - quando não cumprido, afeta aproximadamente um quarto da população brasileira atualmente (de acordo com os últimos dados do IBGE, 2012). No espírito de superar essas dificuldades e contribuir para o devido cumprimento dessas leis, é que são levantadas através deste artigo, a importância da acessibilidade.

Quando se menciona acessibilidade no espaço específico do cemitério Vera Cruz em Passo Fundo, é necessário ir além da existência de vagas de estacionamento para as pessoas com necessidades especiais, e analisar a adaptação do espaço e do entorno como um todo às normas brasileiras de acessibilidade (especificamente em observância da NBR 9050, 2015).

Entende-se que uma vez que o espaço já tenha sido apropriado de forma aleatória, como é o caso aqui, existam particularidades que sem intervenções extremas como a realocação de túmulos, por exemplo, não seria possível alcançar o padrão atual demandado pela norma de acessibilidade. No entanto, mesmo não chegando a estes extremos, podem-se implantar muitas ações que garantam a melhoria desse espaço. Uma delas é a pavimentação plana e/ ou desníveis menores que um centímetro e meio. Quando houver desníveis maiores que $1,5 \mathrm{~cm}$, deve-se instalar caminhos táteis de alerta e de direção, de modo a facilitar o acesso de pessoas com deficiência visual. Junto disso, se faz necessária a ampliação de caminhos para garantir a 
passagem de cadeirantes ou mesmo ampliar o número de unidades de passagem, especialmente nas áreas próximas ao túmulo da Maria Elizabeth e do Mausoléu em homenagem aos soldados da Revolução Constitucionalista, por se tratarem de túmulos que despertam o interesse público. No que diz respeito às rampas, as existentes apresentam atualmente inclinação acentuada, muito acima das previstas em norma; de inclinação igual ou inferior a 8,33\%. Para inclinações intermediárias é recomendado criar áreas de descanso nos patamares, a cada $50 \mathrm{~m}$ de percurso. Há ressalvas relativas à reformas quando esgotadas as possibilidades de soluções que atendam integralmente à norma, ou seja, podem ser utilizadas inclinações superiores a $8,33 \%(1: 12)$ até $12,5 \%$ (1:8); situação que, tecnicamente, é passível de ser aplicada. De qualquer forma, deve-se levar em conta o tipo de ambiente em estudo, já que os usuários onde as pessoas ali presentes estão em situação de trauma e choque.

A norma especifica ainda que quando não houver paredes laterais, as rampas devem incorporar elementos de segurança, como guarda-corpo e corrimãos, instalados ou construídos nos limites da largura da rampa; - na área reservada aos lóculos do segundo pavimento, os guarda-corpos não estão adequados à norma e podem causar acidentes. Vale ressaltar que a altura da queda seria de, no mínimo, um pavimento. Atitudes como essas são preconizadas no Estatuto da Pessoa com deficiência e na Norma brasileira NBR 9050 (2015).

Além das áreas de túmulos e lóculos, existem capelas destinadas aos velórios, distribuídas em diversos locais da cidade. No espaço destinado ao cemitério Vera Cruz propriamente dito, as capelas estão situadas do lado de fora dos muros, no acesso principal; que conta também com estacionamento e uma pequena área com playground, utilizada pela comunidade, além de uma sala destinada ao setor administrativo. Quanto aos acessos ao campo santo, próximo ao estacionamento, existem dois portões. O portão principal se encontra, atualmente, fechado; sendo que a entrada é feita pelo portão secundário, pois este é mais próximo do mausoléu de Maria Elizabeth, considerada a "santinha" local. Assim, os visitantes podem fazer suas devoções de modo acessível, pois este é um dos locais de maior fluxo de pessoas.

Ainda e sob o conjunto maior que é a cidade de Passo Fundo, o cemitério Vera Cruz é um equipamento urbano. No entanto, para fins deste estudo, entende-se o cemitério como uma cidade dentro da cidade e, assim sendo, deve-se considerar a acessibilidade dos equipamentos urbanos deste também, de maneira que banheiros, capelas, áreas de contemplação, ou outros devem ser adaptados de acordo com as normas vigentes. Uma vez que se têm o cemitério como cidade, é importante que seja regido por um plano diretor próprio, já que essa regularização é de extrema importância para evitar que o crescimento aleatório torne o espaço caótico e impeça a devida acessibilidade futuramente.

As vias de circulação interna do cemitério em estudo demonstram ter passado por planejamento em sua origem. Porém, ao longo dos anos e das diversas gestões, estes arruamentos foram desrespeitados e modificados por motivos variados. Hoje, se encontram em situação caótica e desordenada, havendo pouca hierarquia das vias e, em alguns trechos, a inexistência de caminhos entre os elementos construídos e de acesso à alguns túmulos, levando os visitantes a 
passar entre outros jazigos circundantes. O Cemitério Vera Cruz conta com poucos ambientes de permanência, não havendo praças internas ou espaços com bancos para o descanso dos visitantes. A exceção é uma pequena área vegetada com dois bancos, criada por particulares.

Os rituais de sepultamento se completam em um elemento tumular - túmulo ou jazigo. Durante anos, os mortos eram sepultados em covas escavadas lado a lado, que podiam receber acabamentos de materiais diferentes, geralmente de rochas como mármores e granitos; formando os mausoléus. A escassez de espaço nos cemitérios fez com que surgissem novas soluções, como os lóculos e a atual tendência à verticalização dos túmulos, - construções que guardam semelhanças com residências, onde são colocados vários corpos, nos moldes de condomínio; e, em lóculos, ambientes contínuos onde os sepultamentos são realizados em construções verticalizadas, as chamadas gavetas. No Cemitério Vera Cruz há dois espaços reservados aos lóculos: o maior deles instalado ao longo do muro esquerdo do cemitério. São dois pavimentos e o acesso se faz por meio de rampa, de modo a permitir acessibilidade universal.

O que é possível perceber em uma breve análise da paisagem atual do Cemitério Vera Cruz, assim como de grande parte dos cemitérios do país, é que as demandas em relação a dimensionamento e infraestrutura não são atendidas. O Cemitério, como tal, traz em sua existência, contrastes: vida e morte, o mais obvio deles (Figura 3). Mas em termos de arquitetura, percebem-se outros contrastes, tais como: volumes construídos de gabarito mais alto, convivendo com as pequenas lápides de marcação dos túmulos; a (in)acessibilidade oferecida aos vivos; local de descanso eterno e a ausência de assentos para descansar alguns instantes. E, por fim, o contraste entre o Cemitério Vera Cruz, onde quase não se percebe vegetação, - apenas pequenos vasos ornamentais e uns poucos túmulos vegetados; e o Cemitério Israelita, vastamente arborizado.

Não é possível considerar o espaço apropriadamente iluminado e consequentemente seguro, comprometendo o conforto e/a orientação da população visitante. Embora sejam frequentes ações de manutenção como, por exemplo, de limpeza e controle de epidemias, atendendo a solicitações da vigilância sanitária, e mesmo que seja de total responsabilidade de cada família a manutenção e limpeza dos túmulos ou jazigos dos seus familiares, ainda se percebe o atraso nessas questões. Pode-se usar como exemplo de solução a ser estudado, a revitalização do Cemitério da Saudade, em Belo Horizonte, MG, que após o estudo e fiscalização da área, investiu no bem-estar dos visitantes e funcionários. Segundo o CREA (Conselho Regional de Engenharia e Agronomia) de Minas Gerais (2014), o projeto duplicará a capacidade de velórios, construirá lanchonete, banheiros acessíveis para a população transitória, e suporte para os funcionários através de depósitos, almoxarifados, refeitório e vestiários, além de uma intervenção no do sistema de drenagem pluvial.

Figura 3: Cemitério Vera Cruz: Existência x contrastes 

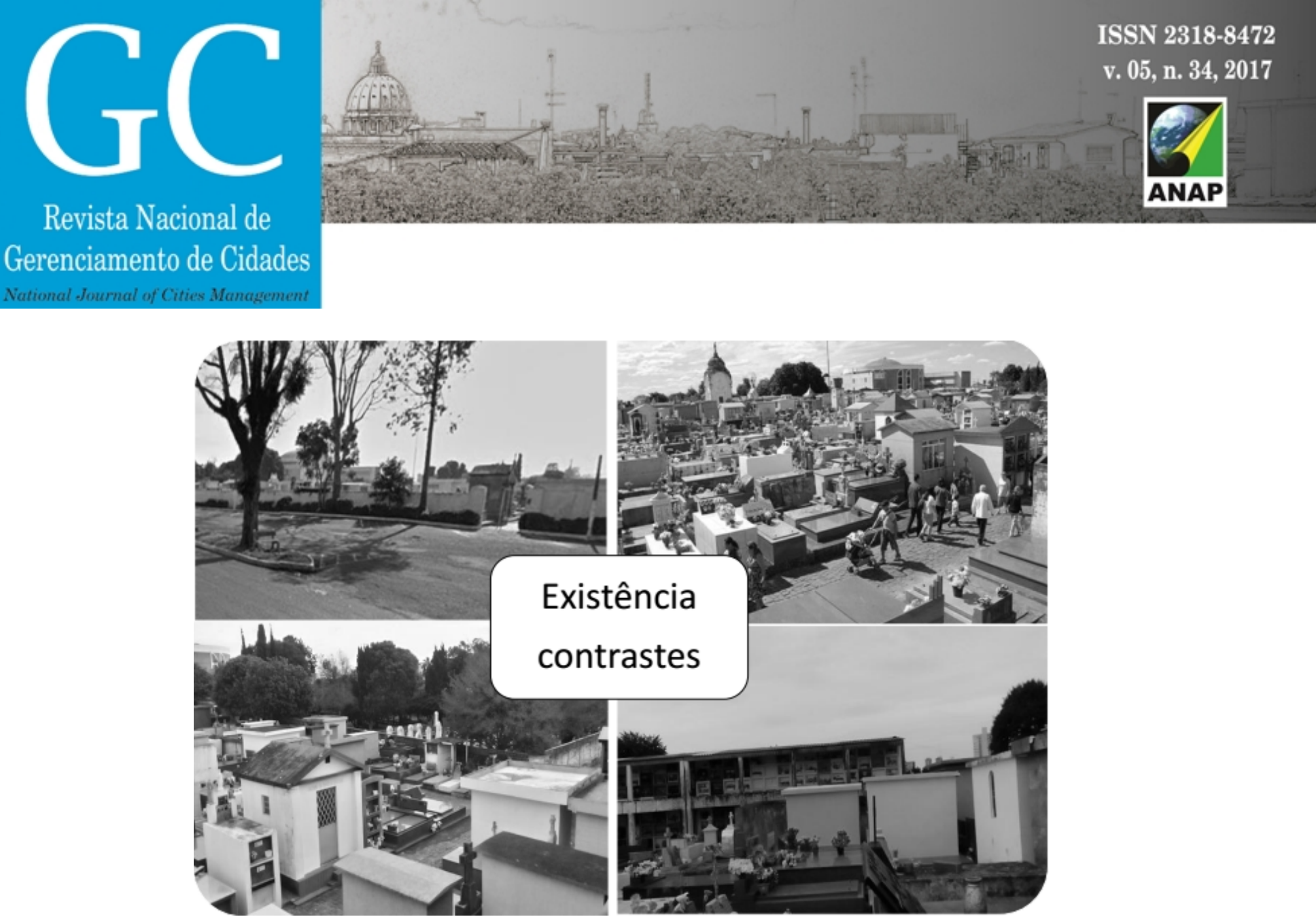

Fonte: Autoras, 2017

Tais condições permitem concluir que os cemitérios devem andar ligados à evolução de suas cidades, as cidades dos vivos. Contudo, o Cemitério Municipal da Vera Cruz não tem acompanhado o rápido e forte processo de desenvolvimento da cidade, indicando a falta de planejamento e infraestrutura pois, quem faz o cemitério não são os mortos, mas os vivos.

\section{Plano diretor}

O processo de urbanização e crescimento da cidade de Passo Fundo assim como de qualquer outro município, traz à tona a atenção que devemos direcionar, através de planos e normas, sobre questões como infraestrutura, segurança e também mobilidade urbana. Nesse sentido, tendo como pressuposto que quanto maior é o número da taxa de natalidade em uma cidade, maior será o número de óbitos nela registrados, o planejamento direcionado aos cemitérios também é um importante fator a ser considerado.

O Plano Diretor, como norma de ordenação da ocupação do território, tem objetivo de orientar as ações do poder público com o objetivo de conciliar os interesses coletivos e garantir que da forma mais correta e segura para todos os projetos executados. Já o código de obras além de garantir a lei uma forma de fiscalização eficaz, garante que as obras estejam dentro de diretrizes básicas como sustentabilidade, qualidade, funcionalidade e acessibilidade.

Ainda tratando da ordenação física dos espaços cemiteriais, o Conselho Nacional do Meio Ambiente, responsável pelo licenciamento ambiental de cemitérios e caracterização da área do empreendimento, por meio da Resolução 335 (BRASIL, 2003) indica que a localização deve estar 
tecnicamente identificada no município, contendo a indicação de acessos, sistema viário, ocupação e agir de forma harmônica com seu entorno. Junto disso, cabe a cada município citar dentro do seu plano diretor e código de obras as especificações que se encaixem dentro dos padrões locais. O que se torna essencial em casos como os de serviços funerários, é a possibilidade de contaminação do solo, ar ou água, devido a liberação de resíduos por parte dos corpos, o que exige atenção na escolha do local de instalação desse equipamento urbano.

Além dos aspectos de ordenação física, o planejamento dos cemitérios deve abordar também questões de preservação desses espaços carregados de simbologia, mensagens e estátuas, o que os torna uma fonte histórica, que possui importantes personagens da história da cidade e do estado. Assim, a arquitetura representa parte de épocas vivenciadas.

A preservação de bens arquitetônicos como é preconizado pelo IPHAN (BRASIL, 2005), no Manual de elaboração de projetos, onde são definidos os procedimentos necessários e específicos, considerando o fato de ser o Bem protegido por lei ou de especial interesse histórico cultural. Dentro desse contexto, a pesquisa histórica visa sistematizar as informações para conhecer e situar a edificação no tempo, identificando sua origem e o seu percurso histórico. 0 levantamento dos dados históricos deve ser, então, suficientemente rigoroso de modo a evitar falsas interpretações e entendimentos equivocados, sendo que um dos instrumentos importantes para a preservação da memória é o seu registro iconográfico.

Os levantamentos, quando geram documentação, funcionam como instrumento para qualquer execução de intervenção restaurativa sobre o monumento, ou seja, o trabalho de levantamento cadastral de um monumento histórico antecede qualquer operação sobre ele, a não ser que represente uma ameaça eminente à integridade física do operador ou do monumento. Nesse caso seria necessário primeiro fazer a estabilização provisória por escoramento.

A documentação não se encerra com o levantamento geométrico do edifício mas, vai além, devendo receber atualização a cada nova informação obtida. Se for o caso, deve conter registros precisos dos achados arqueológicos que antecedem a fase cognitiva, cuja localização é de suma importância para a tomada de decisões futuras.

Para a aplicação dos processos de medição são utilizados um arsenal de instrumentos, como escalas, trenas, teodolitos, níveis, bussolas entre outros. 0 processo mais moderno como a fotografia tradicional ou digital, a fotogrametria e modernas ferramentas computacionais adicionam-se aos recursos tradicionais.

No caso de Passo Fundo, a percepção atual estabelece patrimônio histórico e cultural como o conjunto de bens materiais e imateriais, ambiências, parques urbanos e naturais, praças, sítios e paisagens, assim como manifestações culturais entendidas como tradições, práticas e referências, que confiram identidade ao município. O PDDI - Plano Diretor de Desenvolvimento Integrado (PASSO FUNDO, 2006) define diretrizes para a gestão do patrimônio histórico e cultural do município, buscando fortalecer a identidade e a diversidade cultural pela valorização do patrimônio cultural e histórico, relevar o patrimônio histórico e cultural como fator 
humanizador e de inclusão social e implementar a gestão democrática deste patrimônio, integrando as ações executadas pelas entidades governamentais e não-governamentais.

Durante o ano de 2015, foram realizadas reuniões para a formação do Plano Municipal de Cultura ( $P M C)$, no qual foram arrolados elementos referenciais do patrimônio histórico e cultural da cidade, composto por imóveis e os espaços identificados com a história e a cultura local e regional. Nesse contexto foram inseridos alguns túmulos do Cemitério Vera Cruz, sendo que dois deles já constam das listagens de tombamento municipal: o Decreto № 100/2012, declara bem integrante do patrimônio histórico-cultural do município, para fins de tombamento provisório, a edificação localizada junto ao Cemitério Vera Cruz, conhecida como Mausoléu dos Militares mortos na Revolução Constitucionalista de 1932 e, o Decreto no 183 de 04 de outubro de 2007, que declara bem integrante do patrimônio histórico-cultural do município, a edificação conhecida como o Jazigo de Maria Elizabeth de Oliveira. Além destes, existem também outros exemplares de importância histórico-cultural, que exigem maior atenção e cuidados.

O Mausoléu em homenagem aos soldados na Revolução Constitucionalista de 1932 é ponto referencial dentro do cemitério Vera Cruz. A estrutura passou por recuperação em abril de 2012, quando da presença de quatro técnicos do Exército de Cruz Alta estiveram em Passo Fundo, permanecendo o equivalente há quarenta e cinco dias. Os valores foram custeados pelo Exército Brasileiro.

Trata-se de um monumento histórico e de valor arquitetônico, que estava imêmore há muito tempo, sofrendo os estragos provocados pelo passar dos anos. $O$ trabalho iniciou pela remoção da pintura antiga e passou por várias etapas, como restauração das imagens sacras, vedação das rachaduras, substituição das esquadrias e vidros e, nova pintura. Também foi substituída a rede elétrica.

Além disso, o cemitério Vera Cruz recebe ações de preservação vindas projeto Museu a Céu Aberto, que pretende desenvolver e promover a visitação do cemitério, incentivando a preservação histórico-cultural, bem como a ocupação do espaço, proporcionando maior interação da população com o cemitério em questão. O projeto proporciona, então, visitas guiadas que contemplam personagens que participaram da história da cidade, facilitando a compreensão do presente e evidenciando olhares diferenciados, onde o cemitério não seja visto com o olhar tradicional, reduzido em uma visita a alguém que faleceu, mas com um olhar cultural voltado para história. Estas visitas poderão ser feitas por grupos variados, como escolas e visitantes em geral, bem como sua inclusão no roteiro turístico da cidade.

\section{Considerações finais}

O conhecimento adquirido a respeito do tema, insere uma nova perspectiva, onde pode-se considerar os cemitérios como uma extensão da cidade, que guarda além dos entes queridos, a história e cultura dos seus habitantes. O esquecimento que paira sobre essas áreas está diretamente ligado a falta de valorização cultural do espaço. Entretanto, através da informação 
pode-se divulgar o que há de mais importante e conscientizar os municípios da importância desse patrimônio histórico para a cidade.

Assim, a importância do estudo e valorização do Cemitério Vera Cruz como patrimônio da história e cultura de Passo Fundo é inegável, sendo que um dos instrumentos importantes para a preservação da memória é o seu registro iconográfico, pois é sabido que a imagem pode substituir parcialmente a necessidade de manter contato com o que se foi. No caso da arquitetura nada pode substituir a relação de escala dos edifícios com o seu observador, nada substitui a realidade da pedra, do cimento, do ferro e das leis físicas que governam o organismo estático das precípuas solicitações que deles irradiam. (OLIVEIRA, 2008).

Em decorrência de sua função, o cemitério diferencia-se de seu entorno, caracterizado por zonas residenciais e vias de importância para a conexão entre bairros, que trazem usos diversos. A consolidação deste espaço urbano acabou "engolindo" o cemitério, que fica quase imperceptível na paisagem, especialmente por quem não sabe de sua existência. As exceções ocorrem com o mausoléu dos soldados, construção inserida no cemitério em estudo e com o Memorial da Paz; que, por suas alturas, destacam-se e podem ser vistos a grandes distâncias.

A Prefeitura de Passo Fundo é responsável por todos os cemitérios da cidade. Embora tenha o dever de zelar por esse patrimônio, a responsabilidade pela construção e conservação dos túmulos é do proprietário que adquiriu o lote, ou de sua família. Diversos túmulos em situações precárias são de propriedade de pessoas que não residem atualmente na cidade. O Cemitério Vera Cruz está aos cuidados de um zelador, a visitação é permitida somente no período diurno, medida que auxilia na preservação desse bem.

Os túmulos mais antigos encontrados no levantamento, onde foram sepultados os fundadores da cidade, estão localizados próximos ao mausoléu construído em homenagem aos soldados mortos na Revolução de 1932, que abrigam os restos mortais destes soldados. É importante ressaltar que o referido Mausoléu foi tombado como Patrimônio Histórico de Passo Fundo.

O Cemitério Vera Cruz está em precário estado de conservação, situação verificada nos levantamentos feitos no local, mas ainda guarda um importante acervo histórico que necessita ser estudado.

De acordo com o Poder Executivo e Legislativo de Passo Fundo, ainda não existe um projeto de recuperação ou preservação do Patrimônio Histórico no Cemitério Vera Cruz. Porém, há uma legislação municipal que engloba todo o ambiente municipal na questão de obras históricas, tombamento, preservação cultural, paisagístico e natural; - Museu a Céu Aberto: projeto de tombamento de parte dos túmulos e estuaria do Cemitério Vera Cruz, que tem como propósito, um novo olhar para o Cemitério. Ainda segundo informações do setor administrativo do Cemitério Vera Cruz, tem havido desenvolvimento de pesquisas no âmbito histórico.

Sob a atenção da densidade de visitas que o cemitério recebe diariamente ou em datas memoráveis, é clara a falta de estrutura vigente. Ou seja, fácil perceber que há muito que fazer, de modo à obtenção de segurança, higiene e conforto. Para o meio acadêmico, cemitérios também são um bem patrimonial, e com rico repertório de estudos, onde se podem analisar 
desde o material utilizado nas construções, até os estilos de muitas épocas inseridos em um mesmo local.

\section{Agradecimentos}

Agradecemos às participações voluntárias, na presente pesquisa, das discentes Bruna de Marchi, Cristina Pesente e Maria Anita da Silva do curso de Arquitetura e Urbanismo da UPF pelas contribuições no processo investigativo.

\section{Referencias}

BENÉVOLO, Leonardo. A cidade e o arquiteto. Lisboa: Edições 70, 2006

BRASIL. LEI № 9.503, DE 23 DE SETEMBRO DE 1997. Institui o Código de Trânsito Brasileiro. Disponível em <http://www.planalto.gov.br>. Acesso em fev.17

. LEI № 13.146, DE 6 DE JULHO DE 2015. Institui a Lei Brasileira de Inclusão da Pessoa com Deficiência (Estatuto da Pessoa com Deficiência). Brasília: 2015

. Ministério da Cultura. Instituto do Programa Monumenta. Manual de elaboração de projetos de preservação do patrimônio cultural. Brasília, 2005

. Resolução 335, de 3 de abril de 2003. Dispõe sobre o Licenciamento ambiental de cemitérios. Disponível em < http://www.mma.gov.br/port/conama/legiabre.cfm?codlegi=359>. Acesso em fev.17

. NBR 9050/2015. Acessibilidade a edificações, mobiliário, espaços e equipamentos urbanos. Disponível em <http://www. planalto.gov.br >. Acesso em fev.17

. Cartilha do Censo 2010 - Pessoas com Deficiência / Luiza Maria Borges Oliveira / Coordenação-Geral do Sistema de Informações sobre a Pessoa com Deficiência; Brasília : SDHPR/SNPD, 2012.

HAROUEL, Jean-Louis. História do urbanismo. (Trad. Ivone Salgado). 4ed. Campinas: Papirus, 2004.

OLIVEIRA, Mario Mendonça de. A documentação como ferramenta de preservação da memória. Brasília, DF: IPHAN, Programa Monumenta, 2008, 144p.

MINAS GERAIS. Conselho Regional de Engenharia e Agronomia. Obra de reforma do Cemitério da Saudade, abril 2014. Disponível em< http://www.crea-mg.org.br/publicacoes>. Acesso em fev.17

MORIN, Edgar. O Homem e a Morte. Rio de Janeiro: Imago, 1997. p. 94

MUMFORD, Lewis. A cidade na história: suas origens, transformações e perspectivas. São Paulo: Martins Fontes, 1998.

PASSO FUNDO. Lei complementar no 170, de 09 de outubro de 2006. Dispõe sobre o Plano Diretor de Desenvolvimento Integrado - PDDI do Município de Passo Fundo. Disponível em: $<$ http://www.pmpf.rs.gov.br>. Acesso em: out. 2017. 
. Decreto № 100/2012. Declara bem integrante do patrimônio histórico-cultural do município, para fins de tombamento provisório, a edificação localizada junto ao Cemitério Vera Cruz, conhecida como Mausoléu dos Militares mortos na Revolução Constitucionalista de 1932. Disponível em < https://leismunicipais.com.br >. Acesso em jul.17

Decreto no 183 de 04 de outubro de 2007. Declara bem integrante do patrimônio histórico-cultural do município, a edificação conhecida como o Jazigo de Maria Elizabeth de Oliveira. Disponível em <http://www.pmpf.rs.gov.br/files/dec_183_07.pdf>. Acesso em jul.16 